\title{
Double Star, Cluster, and ground-based observations of magnetic reconnection during an interval of duskward oriented IMF: preliminary results
}

\author{
J. A. Wild ${ }^{1}$, S. E. Milan ${ }^{1}$, J. A. Davies ${ }^{2}$, S. W. H. Cowley ${ }^{1}$, C. M. Carr ${ }^{3}$, and A. Balogh ${ }^{3}$ \\ ${ }^{1}$ Dept. of Physics \& Astronomy, University of Leicester, Leicester LE1 7RH, UK \\ ${ }^{2}$ Rutherford Appleton Laboratory, Didcot, Oxfordshire, OX11 0QX, UK \\ ${ }^{3}$ Blackett Laboratory, Imperial College, London SW7 2BZ, UK
}

Received: 21 January 2005 - Revised: 9 March 2005 - Accepted: 8 April 2005 - Published: 8 November 2005

Part of Special Issue "Double Star - First Results"

\begin{abstract}
We present a space- and ground-based study exploiting data from the coordinated Cluster and Double Star missions in order to investigate dayside magnetic reconnection under $B_{Y}+$ dominated IMF conditions. In-situ observations of magnetosheath flux transfer events combined with measurements of pulsed poleward and dawnward directed flows in the pre-noon sector high-latitude northern hemisphere ionosphere are interpreted as indications of pulsed magnetic reconnection during an interval in which the IMF remained relatively steady. Observations of newlyreconnected magnetic flux tubes anchored in the northern hemisphere both at mid-latitudes and in the vicinity of the subsolar point suggests that during $B_{Y}+$ dominated IMF, reconnection is not, as proposed previously, limited to the highlatitude magnetopause.
\end{abstract}

Keywords. Magnetopause, cusp, arid boundary layers Magnetosheath - Magnetospheric configuration and dynamics

\section{Introduction}

Despite being the principle mechanism by which solar wind energy and momentum are transferred to the magnetosphere, the magnetic reconnection process is not fully understood. The controlling influence that the orientation of the interplanetary magnetic field (IMF) exerts over the location and spatial extent of the reconnection site is still uncertain. It is generally accepted that during periods of southward directed IMF, low latitude or subsolar reconnection plays a dominant role in solar wind-magnetosphere coupling, but during intervals of northward IMF the reconnection site shifts to higher latitudes, most probably in the vicinity of the cusps (e.g. Crooker, 1979; Coleman et al., 2000). However, the location of the reconnection site, or sites, during intervals

Correspondence to: J. A. Wild

(j.wild@ion) of intermediate IMF orientation remains unclear (see Wild et al., 2005, and references therein), although a systematic dawnward/duskward shift of the reconnection region when the dawn-dusk component of the IMF dominates is well documented. In this study we shall introduce ground- and spacebased observations during a favourable conjunction of the Cluster and equatorial Double Star spacecraft (TC-1) with northern hemisphere ionospheric radars. This occurred during an interval of predominantly duskward oriented IMF on 25 March 2004. These data are then employed in order to constrain the location of the reconnection site. For this first results paper, we have limited our exploitation of the insitu data to magnetic field measurement from the TC- 1 and Cluster spacecraft 1 only. A comprehensive multi-spacecraft analysis including plasma measurements will form the basis of a later study.

\section{Instrumentation}

The positions of the various spacecraft relevant to this study are indicated in Fig. 1. During this interval, TC-1 was moving inbound from the magnetosheath to the magnetosphere, encountering the boundary slightly southward of the subsolar point at approximately 07:00 UT. The Cluster spacecraft, moving in the outbound direction, encountered the mid-latitude magnetopause at $\sim 08: 00$ UT. Both of the spacecraft encountered the magnetopause in the 11:00-12:00 MLT sector. In this preliminary review of the data, we shall introduce magnetic field measurements recorded by the fluxgate magnetometer (FGM) experiments on board the Cluster 1 and TC-1 spacecraft (Balogh et al., 2001; Carr et al., 2005, respectively). Ionospheric observations made by the SuperDARN network (Greenwald et al., 1995) and the EISCAT Svalbard radar (ESR: Wannberg et al., 1997) are compared to the in-situ magnetic field measurements recorded by Cluster 1 and TC- 1 . The northern hemisphere SuperDARN radar observations presented here synthesise ionospheric plasma 


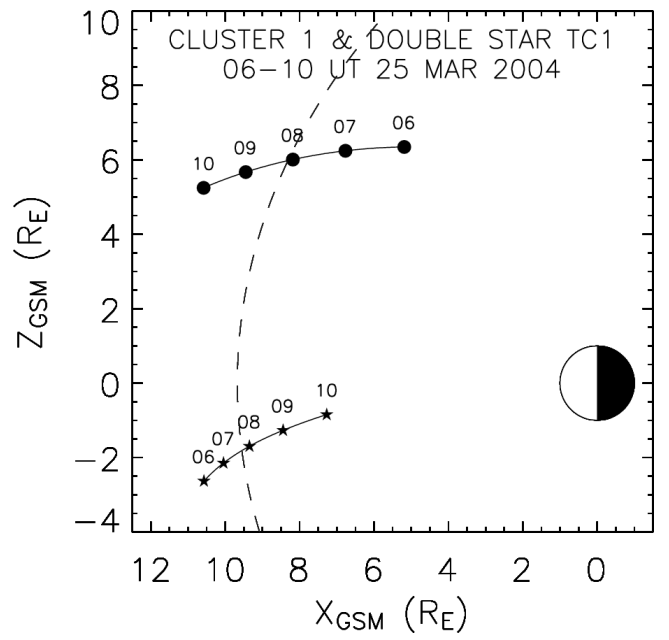

Fig. 1. The locations of the Cluster 1 (circles) and equatorial Double Star (stars) spacecraft in the noon-midnight meridian during the interval under scrutiny. The location of a Shue et al. (1997) magnetopause is also indicated.

velocity measurements from 9 radars using the "map potential" technique of Ruohoniemi and Baker (1998) in order to estimate the global ionospheric convection pattern. We also present measurements of the high-latitude ionosphere made by the $32 \mathrm{~m}$ steerable dish of the incoherent-scatter ESR facility, which was directed northward from Svalbard at low elevation (azimuth $336^{\circ}$, elevation $30^{\circ}$ ). Finally, upstream interplanetary magnetic field conditions are provided by the magnetic fields (MAG) experiment (Smith et al., 1998) on board the Advance Composition Explorer (ACE) spacecraft located some $235 R_{E}$ upstream of the Earth.

\section{Observations}

Figure 2 presents a comparison between the IMF clock angle (defined as $\left.\arctan \left(B_{Y} / B_{Z}\right)\right)$ measured at the ACE spacecraft and the equivalent parameter derived from Cluster 1 and TC- 1 data. The ACE data have been time-shifted by $80 \mathrm{~min}$ in order to account for the propagation delay of IMF structures from the spacecraft to the magnetopause. During the interval that extended from 06:00 to 09:00 UT, the IMF was typically oriented duskward $\left(B_{Y}+\right)$ and northward $\left(B_{Z}+\right)$. The uniform time delay applied to the upstream data brings the ACE clock angle variations into broad agreement with those observed at Cluster 1 and TC- 1 when these spacecraft were located in the magnetosheath. For example, prior to $\sim 07: 00$ UT, TC-1 was located in the magnetosheath where the clock angle orientation closely matched the equivalent lagged IMF data from ACE (i.e. duskward and generally northward). TC-1 entered the magnetospheric cavity at 06:52 UT where it observed the northward pointing magnetospheric field $\left(\sim 0^{\circ}\right.$ clock angle). TC- 1 emerged back into the magnetosheath (or possibly the magnetosheath boundary layer) for approximately $15 \mathrm{~min}$ at $\sim 07: 00 \mathrm{UT}$ before re-

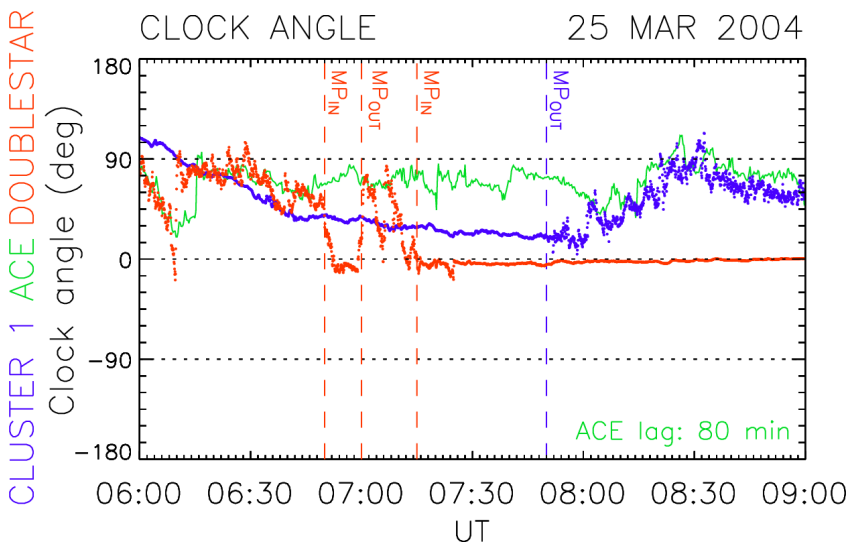

Fig. 2. A comparison of the magnetic field clock angle observed at ACE, Cluster 1, and TC-1 between 06:00-09:00 UT. Cluster 1 and TC-1 magnetopause crossings discussed in the text are indicated by appropriately coloured dashed lines.

entering the magnetosphere for final time. Similar examination of the Cluster 1 magnetic field clock angle indicates that the spacecraft was located within the mid-latitude magnetospheric cavity (northward and duskward oriented magnetic field) until $\sim 07: 50$ UT when the spacecraft emerged into a magnetosheath-like magnetic field configuration. Preliminary plasma data (not shown) indicates that between 07:5008:00 UT Cluster 1 traversed the magnetopause several time, definitively entering the magnetosheath at 08:00 UT.

Figure 3 presents an overview of magnetic field observations from the Double Star TC-1 (Fig. 3a) and Cluster 1 (Fig. 3b) spacecraft. In order to highlight FTEs in the vicinity of the magnetopause boundary, the data are presented in a boundary-normal coordinate system (Russell and Elphic, 1978). More specifically we show the component of the measured magnetic field in the direction normal to the local magnetopause $\left(B_{N}\right)$ and the total magnetic field strength $(|B|)$. In the case of the TC-1 data, the local boundary normal was determined via minimum variance analysis (MVA) of the 07:00 UT magnetopause encounter, the derived unit normal having GSM components $[+0.96,-0.13,-0.25]$. Detailed examination reveals this determination to be robust, as well as being consistent with the expected outward pointing boundary normal in the pre-noon, low (southern) latitude sector. Cluster 1's departure from the magnetosphere was not accompanied by a definitive reorientation of the measured magnetic field. Consequently, MVA proved to be unsatisfactory in determining the boundary normal in the case of this, and the other Cluster spacecraft. Instead, we have estimated the local orientation of the magnetopause by using a Shue et al. (1997) model magnetopause constrained to pass through the location of Cluster 1 at 08:00 UT (the approximate time of the magnetopause crossing). The outward normal to the model magnetopause at this location was thus found to have GSM components $[+0.89,-0.14,+0.42]$.

Inspection of the in-situ magnetometer data reveals characteristic bipolar fluctuations in the $B_{N}$ component of the 

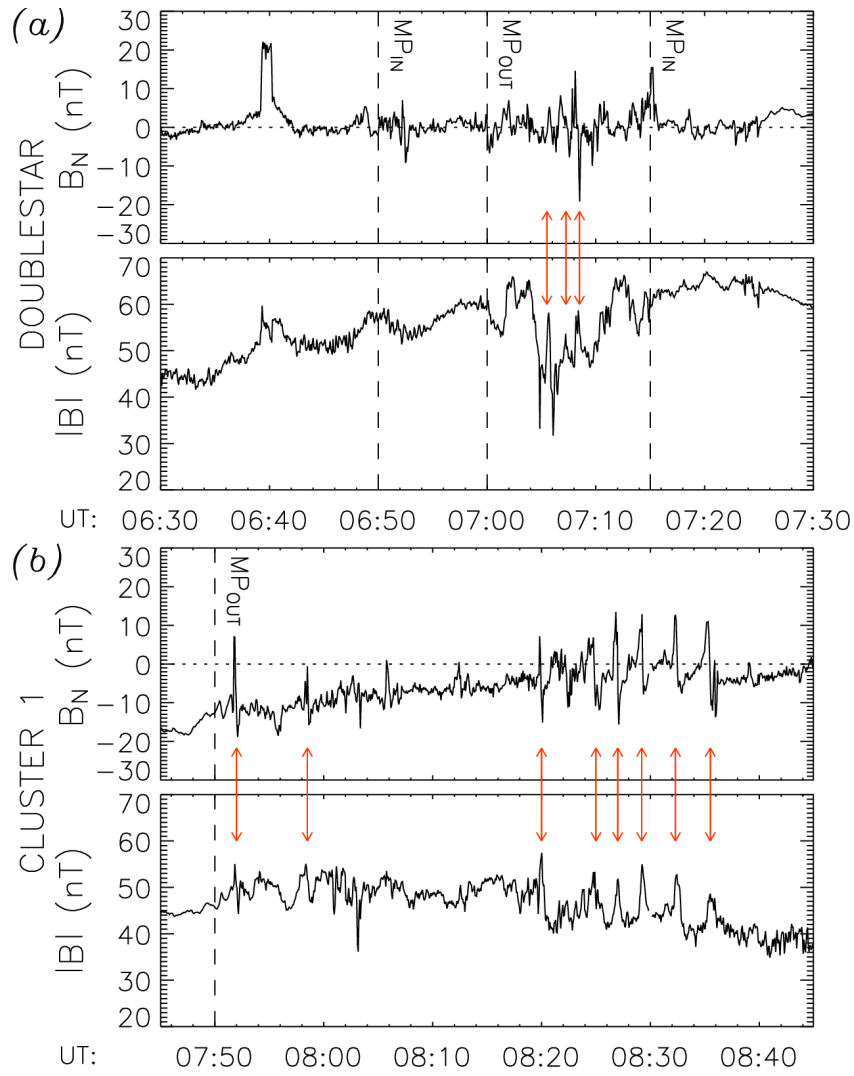

Fig. 3. Magnetic field measurements from the (a) TC-1 and (b) Cluster 1 spacecraft. The component of the magnetic field normal to the local magnetopause and the overall magnetic field strength are presented. Magnetopause crossings and FTEs discussed in the text are indicated by dashed lines and red arrows, respectively.

magnetic field observed at both Cluster and TC- 1 . We interpret these classic FTE signatures as evidence of pulsed magnetic reconnection at the dayside magnetopause. Beginning with the TC-1 data, Fig. 3a presents 60 min of data beginning at 06:30 UT. At this time Cluster was located within the magnetospheric cavity, moving outbound towards the midlatitude pre-noon sector magnetopause. The clearest bipolar signatures occurred when TC-1 was located in the magnetosheath/boundary layer between 07:00 and 07:15 UT. Several large ( $\sim 10 \mathrm{nT}$ peak-to-peak) oscillations were observed, at least three of which appear to be associated with enhancements in $|B|$ (indicated by arrows in Fig. 3a). The timing of these oscillations with respect to the $|B|$ enhancements suggest that these are normal (positive-negative) polarity fluctuations (Russell and Elphic, 1978). Additional FTE-like signatures were also observed at 06:52 UT and from 07:2207:25 UT, although these are less clear and do not appear to be associated with clear $|B|$ enhancements. Observations of FTEs by Cluster 1 began shortly after the spacecraft first encountered the magnetopause at $\sim 07: 50$ UT. The first bipolar FTE signature was observed at 07:52 UT (accompanied by rapid fluctuations in $|B|$ ), with several other clear examples observed over the next $45 \mathrm{~min}$. Figure $3 \mathrm{~b}$ presents data dur-

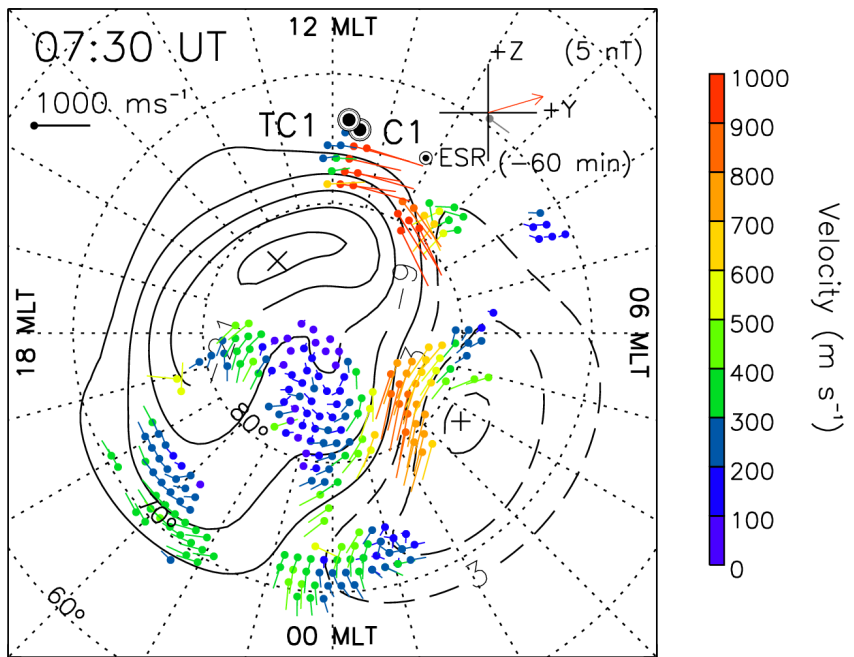

Fig. 4. SuperDARN northern hemisphere ionospheric convection pattern at 07:30 UT on 25 March 2004, derived using the technique of Ruohoniemi and Baker (1998). The location of the ESR and the magnetic footprints of the Cluster 1 and TC- 1 spacecraft are also indicated.

ing the 07:45-08:45 UT interval, by which time TC- 1 was moving at inbound low latitudes towards perigee. The observations culminated in a series of at least 6 classic, normal (positive-negative) polarity bipolar oscillations. In these cases, the bipolar perturbations were associated with $|B|$ enhancements and field-tilting effects in the plane of the magnetopause (not shown). The observed bipolar FTE signatures at both spacecraft exhibited normal polarity were indicative of northern hemisphere flux tubes contracting northward under the action of the field tension following magnetic reconnection (e.g. Russell and Elphic, 1978).

When in the magnetosphere, the northern hemisphere ionospheric footprints of both Cluster and Double Star were located within the fields-of-view of the easternmost pair of SuperDARN radars. Figure 4 presents the ionospheric convection pattern at 07:30 UT, inferred from all available northern hemisphere SuperDARN data. At this time, both spacecraft were located within the magnetosphere, TC-1 having recently traversed the low latitude magnetopause from the magnetosheath (where FTEs were observed), while Cluster 1 was approaching the mid-latitude magnetopause (where FTE signatures were also observed). The estimated ionospheric flow pattern is as expected for convection driven by a dominant IMF $B_{Y}$ component (in this case duskward) with ionospheric plasma in the noon sector flowing dawnward and poleward into the polar cap as newly reconnected magnetic field lines, one end of which remains embedded in the solar wind, respond to magnetic tension forces and the influence of the anti-sunward directed solar wind flow. Detailed examination of line-of-sight velocity measurements from individual radars located in the noon and pre-noon sector reveals pulsed ionospheric flows (PIFs) - bursts of high speed $\left(\sim 1000 \mathrm{~m} \mathrm{~s}^{-1}\right)$ ionospheric plasma flow directed into 


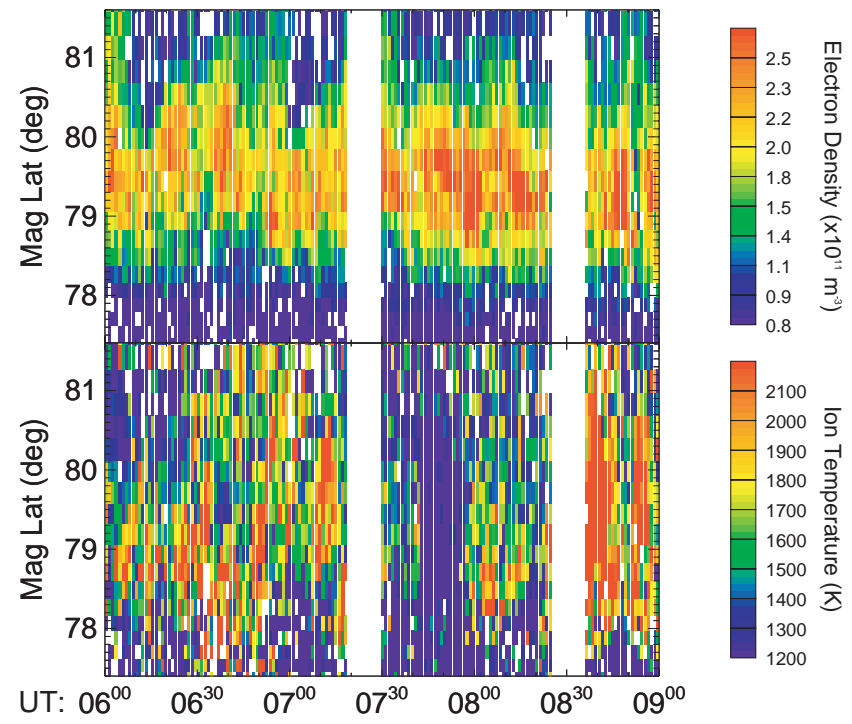

Fig. 5. Ionospheric electron density and ion temperature measurements made by the ESR during the interval of interest.

the polar cap (for a discussion of PIFs, see Wild et al., 2001). The ESR also recorded poleward moving structures in the high-latitude ionosphere north of Svalbard (MLT $\sim \mathrm{UT}+3 \mathrm{~h}$ ). Figure 5 presents an overview of electron density and ion temperature measurements during the 3-h interval of interest. Regions of elevated ion temperature, which can be considered a proxy for enhanced ion flow velocity, were observed moving poleward at $\sim 1.5 \mathrm{~km} \mathrm{~s}^{-1}$. While requiring further detailed anlysis, these structures appear to be roughly correlated with depletions in the measured ionospheric electron density (the enhanced ion temperatures most likely resulting in an increased rate of electron-ion recombination).

\section{Discussion \& conclusions}

The 07:30 UT satellite footprints shown in Fig. 4 indicate the ionospheric region corresponding to reconnecting magnetospheric field lines located adjacent to the magnetopause. On 25 March 2004, this region was situated in the vicinity of the EISCAT Svalbard radar and elements of the SuperDARN radar network. Just prior to this time, the TC-1 spacecraft had observed magnetosheath FTEs in the vicinity of the subsolar region. Shortly afterwards, the Cluster spacecraft observed FTEs at the same magnetic local time, but in the mid-latitude magnetosphere/magnetosheath. Although the observations of FTEs were separated by $\sim 1 \mathrm{~h}$, the IMF conditions remained approximately constant throughout (i.e. duskward dominated but generally northward pointing). We therefore infer that during this interval dayside magnetic reconnection was relatively steady, resulting in the FTE signatures observed at the low- and mid-latitude magnetopause. Given the steady IMF conditions, we consider it likely that the multiple magnetopause encounters recorded by $\mathrm{TC}-1$ were a result of variations in the solar wind dy- namic pressure (although the unavailability of upstream solar wind plasma data does not allow us to confirm this). The pulsing of ionospheric plasma flow dawnwards and polewards across the high-latitude noon-sector ionosphere, as observed by the ESR and SuperDARN radars, is further evidence of magnetic reconnection at the dayside ionosphere driving ionospheric convection typical of $+B_{Y}$ dominated IMF conditions. Bursty flows such as the observed PIFs are now accepted as the ionospheric counterparts of FTEs. While the temporally displaced in-situ observations presented here do not allow a one-to-one comparison of FTEs at widely separated latitudes, they are evidence of newly-reconnected magnetic flux tubes propagating over much of the surface of the magnetopause, including the subsolar region, during $B_{Z}>0,\left|B_{Y}\right| \gg B_{Z}$ IMF conditions. This is not consistent with an antiparallel description of magnetic reconnection under $B_{Y}+$ dominated IMF conditions (e.g. Crooker, 1979) which suggests that newly-opened flux tubes would not traverse the subsolar region, as they appear to do here. A future investigation will therefore consider the motion and recent history of reconnected magnetic field lines in this region under $B_{Y}$ dominated IMF conditions.

Acknowledgements. We thank the ACE Science Center and the EISCAT scientific association for the data presented here. Research at Leicester was supported by PPARC grant number PPA/G/O/2003/0013.

Topical Editor T. Pulkkinen thanks O. Amm and K. A. McWilliams for their help in evaluating this paper.

\section{References}

Balogh, A., Carr, C. M., Acuna, M. H., et al.: The Cluster Magnetic Field Investigation: overview of in-flight performance and initial results, Ann. Geophys., 19, 1207-1217, 2001,

SRef-ID: 1432-0576/ag/2001-19-1207.

Carr, C., Brown, P., Zhang, T. L., et al: The Double Star magnetic field investigation: instrument design, performance and highlights of the first year's observation, Ann. Geophys., 23, 27132732, 2005.

Coleman, I. J., Pinnock, M., and Rodger, A. S.: The ionospheric footprint of antiparallel merging regions on the dayside magnetopause, Ann. Geophys., 18, 511-516, 2000,

SRef-ID: 1432-0576/ag/2000-18-511.

Crooker, N. U.: Dayside merging and cusp geometry, J. Geophys. Res., 84, 951-959, 1979.

Greenwald, R. A., Baker, K. B., Dudeney, J. R., et al.: Darn/SuperDARN: a global view of the dynamics of highlatitude convection, Space Sci. Rev., 71, 761-796, 1995.

Ruohoniemi, J. M. and Baker, K. B.: Large-scale imaging of highlatitude convection with Super Dual Auroral Radar Network HF radar observations, J. Geophys. Res., 103, 20 797-20 811, 1998.

Russell, C. T. and Elphic, R. C.: Initial ISEE magnetometer results: magnetopause observations, Space Sci. Rev., 22, 681-715, 1978.

Shue, J.-H., Chao, J. K., Fu, H. C., et al.: A new functional form to study the solar wind control of the magnetopause size and shape, J. Geophys. Res., 102, 9497-9511, 1997.

Smith, C. W., Acuna, M. H., Burlaga, L. F., et al.: The ACE Magnetic Fields Experiment, Space Sci. Rev., 86, 613-631, 1998. 
Wannberg, G., Wolf, L., Vanhainen, L. G., et al.: The EISCAT Svalbard radar: A case study in modern incoherent scatter radar system design, Radio Sci., 32, 2283-2308, 1997.

Wild, J. A., Cowley, S. W. H., Davies, et al.: First simultaneous observations of flux transfer events at the high-latitude magnetopause by the Cluster spacecraft and pulsed radar signatures in the conjugate ionosphere by the CUTLASS and EISCAT radars, Ann. Geophys., 19, 1491-1508, 2001,

SRef-ID: 1432-0576/ag/2001-19-1491.
Wild, J. A., Milan, S. E., Cowley, S. W. H., et al.: Simultaneous insitu observations of the signatures of dayside reconnection at the high and low latitude magnetopause, Ann. Geophys., 23, 445460, 2005,

SRef-ID: 1432-0576/ag/2005-23-445. 